\begin{tabular}{|c|c|}
\hline 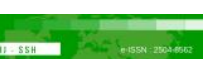 & Malaysian Journal of Social Sciences and Humanities (MJSSH) \\
\hline Malaysian Journal of & Volume 6, Issue 6, June 2021 \\
\hline (MJ-SSH) & e-ISSN : 2504-8562 \\
\hline & $\begin{array}{l}\text { Journal home page: } \\
\text { www.msocialsciences.com }\end{array}$ \\
\hline
\end{tabular}

\title{
Kajian Faktor-Faktor Penyebab Buruh Binaan Asing Menjadi Pilihan Majikan
}

\author{
Faizah Binti Hj. Zainal Abidin'1 \\ 1Politeknik Sultan Abdul Halim Mu'adzam Shah (POLIMAS), Kedah \\ Correspondence: Faizah Binti Hj. Zainal Abidin (faizah1480@gmail.com)
}

\begin{abstract}
Abstrak
Pertumbuhan sektor pembinaan seperti pembinaan kemudahan infrastruktur, perumahan dan bangunan telah banyak memberi sumbangan kepada pertumbuhan ekonomi negara. Hasil daripada kerancakan pertumbuhan ini, keperluan terhadap guna tenaga di dalam memenuhi permintaan pembangunan menjadi semakin meningkat. Namun begitu, sektor pembinaan pada masa sekarang masih lagi bergantung kepada khidmat gunatenaga asing akibat kekurangan gunatenaga tempatan yang kurang berminat menyebabkan kehadiran buruh asing di tapak pembinaan boleh dikatakan sangat ketara. Malah, terdapat di sesetengah tapak pembinaan hampir 90 peratus daripada pekerjanya adalah buruh asing. Melihat kepada keadaan ini satu kajian telah dilakukan bagi mengkaji faktor-faktor penyebab buruh asing menjadi pilihan utama kontraktor berbanding dengan buruh tempatan. Kajian ini dibataskan kepada 21 buah syarikat kontraktor di negeri Pulau Pinang dan juga negeri Kedah bagi semua kelas iaitu kelas A hingga F. Data yang dikumpul melalui kaedah borang soal selidik dianalisis menggunakan perisian Microsoft Excel dan SPSS. Dapatan kajian mendapati 60.90 peratus daripada keseluruhan buruh di tapak bina adalah buruh asing. Manakala faktor-faktor buruh asing menjadi pilihan responden berbanding buruh tempatan adalah disebabkan faktor upah yang murah, kemahiran kerja yang tinggi, tahan lasak, sanggup bekerja lebih masa, disiplin kerja yang tinggi serta boleh bekerja di dalam kumpulan yang besar. Dapatan kajian terhadap ciri-ciri pilihan kontraktor dalam pemilihan buruh, bagi buruh asing ciri-ciri seperti upah yang rendah, pekerja lelaki berumur 18 tahun sehingga 40 tahun, ketahanan kerja, kerja lebih masa serta kemahiran yang tinggi menjadikan mereka sebagai pilihan utama responden berbanding dengan buruh tempatan.
\end{abstract}

Kata kunci: buruh, buruh asing, buruh tempatan, pembinaan, pilihan majikan

\section{A Study of the Factors Causing Foreign Construction Labor to Become Employers' Choice}

\begin{abstract}
The growth of the construction sector such as the infrastructure, housing and building has provided massive benefits to the growth of the economy. The advantage of this growth leads to an increment in the demand of employees. But, due to lack of interest to work in the construction industry of employees from our country, the construction sector needs to employ people from foreign countries. Due to this situation, in certain cases, almost $90 \%$ of the employees are foreign workers. Acknowledging this situation, this research has been done to identify the factors involved on why foreign workers are the priorities of contractors instead of labors from Malaysia. This research is limited to 21 companies of contractors from A to F class from the state of Penang and Kedah. The data that has been collected using
\end{abstract}


self-administered questionnaire was analyze using Microsoft Excel. The result indicated that $60.9 \%$ of the employees at the construction sites are foreign workers. The result also explains that the factors involved on why foreign workers has been prioritized are cheaper wage, better skills, physically and mentally tougher, willing to work overtime, better discipline and are prepared to work in groups. In addition, the main criteria contractors utilize to choose foreign workers are wage, male age between 18 to 40 years, strong, skillful and willingness to work overtime made the foreign workers are a better choice compared to Malaysian labor.

Keywords: labor, foreign labor, local labor, construction, employer choice

\section{Pengenalan}

Sejak akhir-akhir ini,lambakan tenaga pekerja asing begitu ketara dibawa masuk ke negara ini bagi menampung keperluan tenaga kerja dalam pelbagai sektor terutamanya sektor pembinaan, perkilangan dan pembuatan, perladangan dan perkhidmatan. Pada tahun 2002, terdapat lebih 800,000 orang pekerja asing di Malaysia yang bekerja di dalam pelbagai sektor terutamanya sektor pembinaan, perkilangan serta sektor perkhidmatan (Laporan Berita Harian, 2002). Puncanya disebabkan kekosongan yang sepatutnya diisi oleh pekerja tempatan yang dikatakan terlalu memilih pekerjaan serta permintaan terhadap ganjaran yang tinggi menyebabkan pihak majikan atau kerajaan membuka peluang kepada pekerja-pekerja asing untuk mengatasi masalah kekurangan tenaga kerja di pelbagai sektor.

Pada 2002, kerajaan telah mengumumkan supaya tenaga kerja warga asing terutamanya dari Indonesia perlu dihantar pulang atau pengurangan penggunaan tenaga buruh asing terutama sekali dalam sektor pembinaan. Akibatnya sektor itu telah mengalami waktu suram disebabkan banyak projek-projek pembinaan tidak dapat berjalan dengan lancar mengikut perancangan atau projek terbengkalai. Menurut Menteri Kerja Raya, Datuk Seri S. Samy Vellu (Berita Harian, 30 Januari 2002) pembangunan di Malaysia akan terjejas sedikit terutamanya dalam sektor pembinaan apabila kerajaan mengambil langkah mengurangkan jumlah pekerja asing, terutamanya Indonesia. Mengikut cacatan rasmi, terdapat seramai 588,000 orang pekerja rakyat Indonesia di negara ini daripada keseluruhan 790,000 orangpekerja asing berdaftar (Utusan Malaysia, 25 Januari 2002).

Sehubungan itu, jelas sekali mendapati bahawa kebergantungan kerja terhadap tenaga buruh asing terutama dalam sektor pembinaan menjadi pilihan kontraktor. Kesanggupan majikan menggunakan tenaga buruh asing berbanding buruh tempatan dalam sektor ini juga telah memberi kesan terhadap peratusan pengangguran rakyat dan juga kadar aliran wang ke luar negara (penghantaran wang balik oleh pekerja-pekerja asing). Menurut Ketua Polis Negara, Datuk Musa Hassan kepada Berita Bernama (Februari, 2007), pada masa sekarang jumlah pekerja asing di Malaysia melebihi 1.8 juta orang termasuk 500 ribu orang merupakan pendatang asing tanpa azin (PATI). Dengan kebanjiran pekerja asing di Malasyia yang ramai mampu mengugat keselamatan negara. Beliau mencadangkan agar pihak kerajaan mengurangkan pengambilan pekerja asing untuk bekerja di negara ini terutama di sektor pembinaan serta menegaskan agar pihak majikan tidak mementingkan aspek kos upah yang rendah semata-mata. Ciri-ciri pekerja tempatan yang mahir serta mudah berkomunikasi dan juga mudah memahami arahan kerja belum mampu menarik minat kontraktor untuk digunakan sebagai pekerja di tapak-tapak pembinaan. Mereka lebih suka untuk menggunakan khidmat pekerja asing berbanding pekerja tempatan. Dengan situasi begini, maka penyelidik amat tertarik untuk mengkaji faktor-faktor penyebab buruh asing menjadi pilihan utama kontraktor berbanding buruh tempatan.

\section{Sorotan Literatur}

Konsep tenaga buruh yang paling luas ialah jumlah tenaga buruh, ditakrifkan sebagai jumlah dalam satu-satu minggu individu yang berusia 16 tahun ke atas yang tidak diinstitusikan sama ada sedang bekerja atau menganggur (Don Bellante dan Mark Jackson, 1983). Klasifikasi seseorang yang bekerja adalah seperti berikut: 
- Jika seseorang itu melakukan sebarang kerja untuk mendapatkan upah di sepanjang minggu (dianggap sama bagi pekerja yang bekerja selama 4 jam atau $40 \mathrm{jam})$.

- Individu yang bekerja di sepanjang minggu tanpa mendapat bayaran (perusahaan kendalian keluarga).

- Individu yang tidak langsung bekerja di sepanjang kajian namun mempunyai pekerjaan (cuti, sakit atau cuaca buruk).

Menurut Akta Kerja 1955, mendefinisikan 'pekerja' sebagai mana-mana orang atau golongan orang yang dimaksudkan dalam mana-mana kategori dalam Jadual Pertama atau berkaitan dengan orang yang mana Menteri membuat perintah di bawah subseksyen (3) atau 2A. Jadual Pertama mendefinisikan pekerja seperti berikut:

- Seseorang yang bekerja dengan sesuatu majikan di mana mendapat upah tidak melebihi RM 1,500.00.

- Seseorang yang bekerja tanpa mengambil kira kadar upahnya dalam sebulan seperti:

i. Kerja-kerja kasar seperti tukang atau buruh.

ii. Terlibat dalam kerja pembaikpulih kenderaan berjentara.

iii. Sebagai penyelia kepada pekerja di bawahnya.

iv. Kerja-kerja atas kapal yang berdaftar di Malaysia.

v. Kakitangan domenstik.

Undang-Undang Buruh di Malaysia telah menetapkan umur yang tertentu bagi membolehkan seseorang itu bekerja untuk menampung hidupnya. Menurut Ahmad Sobri (2005), had umur bagi tenaga buruh untuk bekerja adalah 15 hingga 64 tahun sama ada bekerja atau menganggur, dan maksud pekerja pula adalah seseorang yang bekerja sama ada untuk majikan awam atau persendirian dan menerima ganjaran tetap seperti upah, komisen, yang berbentuk mata benda. Manakala menurut Ahmad Sobri (2005), buruh binaan merupakan orang yang bekerja untuk membina atau mendirikan sesuatu bingunan. Secara amnya, teori penggunaan buruh adalah berkaitan dengan aspek penawaran dan permintaan. Buruh juga dikategorikan kepada tiga iaitu buruh mahir, separa mahir dan buruh tidak mahir (Mhd Azmin, 2001). Terdapat juga personel yang lain selain daripada ketiga-tiga tersebut iaitu mandur. Mandur juga perlu dikira dalam kos buruh walaupun hanya melakukan kerjakerja penyeliaan sahaja.

Industri pembinaan di Malaysia adalah juga seperti di negara-negara lain dianggap sebagai enjin pertumbuhan ekonomi dan boleh menunjukkan keadaan ekonomi negara. Aktivti-aktiviti pembinaan yang banyak menunjukkan arah bahawa ekonomi negara adalah berkembang dan kekurangan pembinaan akan bermakna ekonomi negara adalah meleset.

Pertumbuhan sektor pembinaan mempunyai banyak kesan limpahan ke atas ekonomi negara. Sektor ini telah mengalami penguncupan semenjak tahun 2004 (Rajah 1). Walau bagaimanapun, sektor ini dijangka kembali pulih pada tahun 2007. Perbelanjaan sektor awam, terutamanya bagi pembinaan kemudahan infrastruktur, perumahan dan bangunan telah banyak memberi sumbangan kepada pertumbuhan sektor pembinaan. Peruntukan pembangunan 27.5 bilion ringgit disediakan bagi pelbagai projek pembinaan pada tahun 2007. di samping itu, empat billion ringgit akan dibelanjakan untuk beberapa projek PFI dalam tahun 2007 (Laporan Bajet 2007, Berita Harian.online, 2006).

Hasil daripada kerancakan pertumbuhan industri binaan ini, keperluan terhadap guna tenaga di dalam memenuhi permintaan pembangunan menjadi semakin meningkat. Walaupun begitu, Malaysia pada masa sekarang masih lagi bergantung kepada khidmat gunatenaga asing akibat kekurangan gunatenaga tempatan yang kurang berminat dalam bidang pembinaan. Menurut Laporan Ekonomi (Utusan Malaysia, September 2004), kerajaan telah meluluskan pengambilan sebanyak 269,100 buruh asing atau 19.8 peratus pada pertengahan pertama tahun 2004 untuk mengisi kekosongan yang 
DOI: https://doi.org/10.47405/mjssh.v6i6.811

ditinggalkan atau masih belum diisi oleh pekerja tempatan dan menyeimbangkan perkembangan sektor pembinaan negara.

Rajah 1 : Gunatenaga Industri Pembinaan

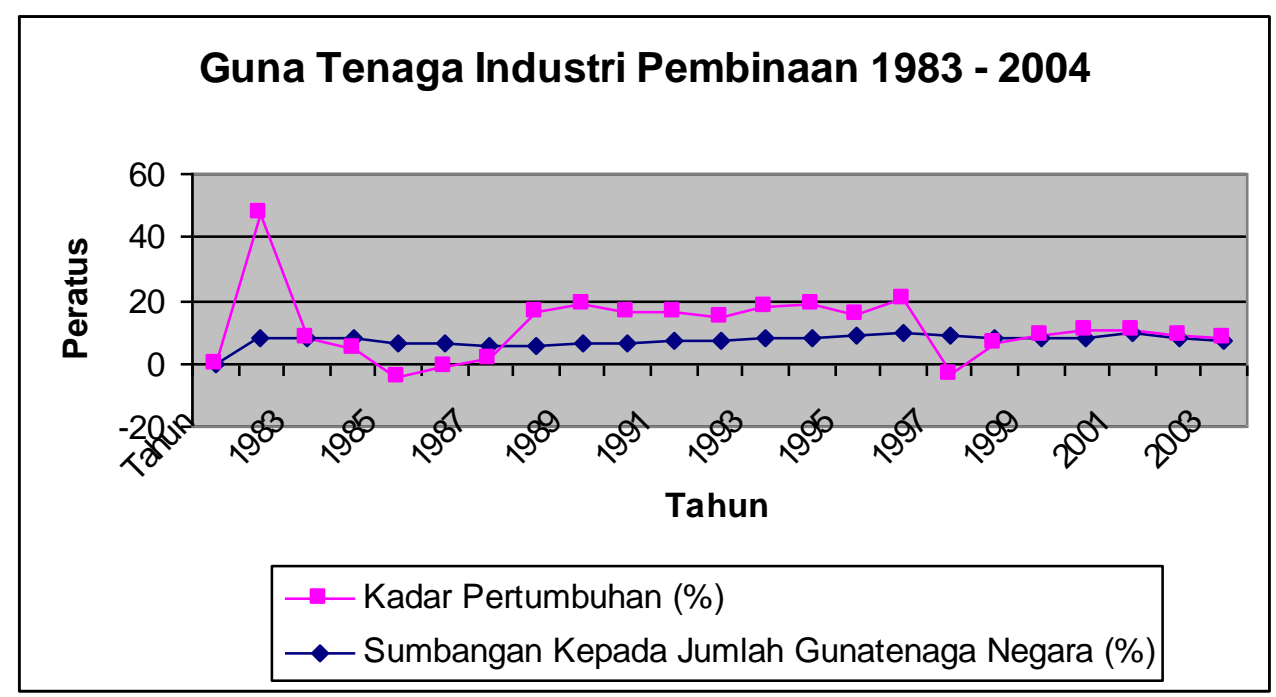

Dalam penggunaan buruh binaan, penggunaan buruh asing diambil bagi menggantikan pekerja tempatan disebabkan oleh faktor kos upah yang murah, kualiti kerja, mudah urus kira dan berbagai lagi. Menurut Teoh Chew Chee (1986), empat faktor utama yang mempengaruhi keadaa pasaran buruh yang perlu kita lihat untuk mendapatkan gambaran tentang bekalan tenaga kerja luar ialah:

- Perkembangan demografi.

- Keadaan ekonomi.

- Keadaan pasaran tempatan.

Sumber utama bekalan buruh ialah tenaga buruh yang terdapat di dalam negeri (tempatan) serta sumber-sumber dari luar (penggunaan buruh sama ada tempatan dan juga asing).

\section{Takrifan Buruh dan Penggunaan Buruh dalam Sektor Pembinaan}

Malaysia kini telah mencapai guna tenaga penuh, jumlah tenaga buruh meningkat dari tahun ke tahun menyebabkan Malaysia memerlukan lebih ramai tenaga buruh untuk terus membangun. Tidak dapat dinafikan pengambilan buruh daripada luar negara telah menyumbang kepada pembangunan industri pembinaan negara khasnya dan sektor-sektor lain amnya. Kebenaran pihak kerajaan membenarkan pengimportan tenaga buruh asing ini dapat mengurangkan masalah projek terjejas akibat kekeurangan pekerja, walaupun terdapat beberapa pandangan negatif hasil dari kedatangan dan kemasukan pekerja asing yang ramai dan pelbagai masalah sosial, keperluan kepada pekerja asing perlun dilihat dari segi sumbangan kepada pertumbuhan ekonomi secara menyeluruh (Mohd Asri Abdullah, 1997). Jika dilihat kepada Jadual 1 mengenai agihan buruh asing mengikut sektor dan juga negara menunjukkan bahawa seramai 659,283 orang telah diambil sebagai buruh asing di pelbagai sektor yang mewakili lebih daripada sepuluh buah negara sehingga tahun 1997. Malah, dalam sektor pembinaan sendiri seramai 186,195 buruh digunakan untuk meningkat dan memperkembangkan industri ini di mana ianya merupakan sektor yang paling banyak sekali menggunakan tenaga kerja asing. 
DOI: https://doi.org/10.47405/mjssh.v6i6.811

Jadual 1 : Agihan Penggunaan Buruh Asing Di Malaysia (Julai 1992 - Januari 1997)

\begin{tabular}{l|ccccccc}
\hline $\begin{array}{l}\text { Sektor/ } \\
\text { Negara }\end{array}$ & Domestik & Pertanian & Pembinaan & Perkhidmatan & Perkilangan & Lain-lain & JUMLAH \\
\hline Indonesia & 100,324 & 139,701 & 124,777 & 4,154 & 30,773 & 1,047 & 400,776 \\
Thailand & 3,881 & 22,536 & 12,080 & 1,534 & 298 & 748 & 41,077 \\
Filipina & 44,539 & 49 & 1,160 & 828 & 1,401 & 568 & 48,545 \\
Bangladesh & 56 & 32,271 & 44,603 & 6,719 & 76,326 & 316 & 160,291 \\
Pakistan & 53 & 183 & 1,356 & 435 & 1,694 & 3 & 3,724 \\
India & 54 & 306 & 1,347 & 446 & 198 & 27 & 2,378 \\
Sri Langka & 5 & 4 & 43 & 39 & 28 & - & 119 \\
Myanmar & 17 & 125 & 675 & 282 & 125 & 16 & 1,240 \\
Nepal & $\mathrm{NA}$ & 25 & 17 & 97 & 262 & $\mathrm{NA}$ & 401 \\
Nigeria & $\mathrm{NA}$ & $\mathrm{NA}$ & $\mathrm{NA}$ & $\mathrm{NA}$ & $\mathrm{NA}$ & 5 & 5 \\
Lain-lain & 7 & $\mathrm{NA}$ & 137 & 11 & 54 & 518 & 727 \\
JUMLAH & 148,936 & 195,200 & 186,195 & 14,545 & 111,159 & 3,248 & 659,283 \\
\hline
\end{tabular}

Sumber: Mohd Isa et.al. (1999) m.s 47.

Jadual 2 : Agihan Buruh Asing Mengikut Jantina, Etnik dan Sektor

\begin{tabular}{|c|c|c|c|c|c|c|}
\hline \multirow{2}{*}{ Sektor } & \multicolumn{2}{|c|}{ Rakyat Bangladesh } & \multicolumn{2}{|c|}{ Rakyat Indonesia } & \multicolumn{2}{|c|}{ Rakyat Filipina } \\
\hline & Lelaki & Wanita & Lelaki & Wanita & Lelaki & Wanita \\
\hline $\begin{array}{l}\text { Perkhidmatan } \\
(\mathrm{N}=41)\end{array}$ & $21(28 \%)$ & - & $8(21.1 \%)$ & $12(19.4 \%)$ & - & - \\
\hline $\begin{array}{l}\text { Perkilangan } \\
(\mathrm{N}=199)\end{array}$ & $24(32 \%)$ & $25(100 \%)$ & - & $50(80.6 \%)$ & $5(100 \%)$ & $95(100 \%)$ \\
\hline $\begin{array}{l}\text { Pembinaan } \\
(\mathrm{N}=60)\end{array}$ & $30(40 \%)$ & - & $30(78.9 \%)$ & - & - & - \\
\hline $\begin{array}{l}\text { JUMLAH } \\
(\mathbf{N}=\mathbf{3 0 0})\end{array}$ & $75(100 \%)$ & $25(100 \%)$ & $38(100 \%)$ & $62(100 \%)$ & $5(100 \%)$ & $95(100 \%)$ \\
\hline
\end{tabular}

Sumber : Mohd Isa et.al. (1999) m.s 50.

Berdasarkan statistik-statistik yang telah ditunjukkan menunjukkan penggunaan buruh asing semakin meningkat. Menurut Mohd Isa et.al. (1999), punca-punca kepada kedatangan pekerja asing ke Malaysia adalah seperti berikut:

- Keadaan ekonomi semasa negara.

- Permintaan pasaran buruh.

- Kuasa kerja berdasarkan sektor.

- Kuasa kerja berdasarkan gaji atau upah.

\section{Ciri-ciri Pemilihan Buruh Asing dan Masalah Tenaga Buruh Binaan Pekerja Tempatan dan Buruh Asing}

Malaysia yang mengamalkan ekonomi terbuka (open economy) menyebabkan negara ini dikenali ramai dan seterusnya telah menarik lebih ramai pelabur asing untuk melabur di Malaysia. Ini seterusnya menyebabkan ekonomi Malaysia terus berkembang. Perkembangan ini secara langsung menyebabkan Malaysia memerlukan lebih ramai tenaga kerja, profesional, separa profesional serta pekerja mahir, separa mahir dan buruh am. Namun begtu, tenaga kerja di Malaysia terutamanya tenaga buruh tidak mencukupi 
khususnya dalam sektor pembinaan. Oleh yang demikian, peluang kerja yang banyak ini telah menarik minat buruh asing untuk berhijrah ke Malaysia bagi mengisi kekesongan tersebut sama ada secara sah ataupun secara tidak sah.

Mereka yang datang ini dari pelbagai negara yang berjiran dengan Malaysia terutamanya Indonesia, Thailand, Myanmar, Filipina, Bangladesh dan lain-lain. Menurut Ahmad Sobri (2005), hampir 69 peratus daripada 10 kontraktor di Kedah menggunakan khidmat buruh asing berbanding 31 peratus yang menggunakan buruh tempatan. Manakala hampir 100 peratus kontraktor yang dikaji menggunakan buruh dari Indonesia dalam projek pembinaan mereka. Begitu juga dengan pilihan tenaga buruh oleh kontraktor bagi projek yang akan datang di mana khidmat buruh asing masih diperlukan iaitu dengan peratusan 58.3 peratus berbanding buruh tempatan (Ahmad Sobri, 2005). Berdasarkan statistik ini menunjukkan kebanyakan kontraktor lebih gemar untuk menggunakan khidmat buruh asing berbanding buruh tempatan. Jadi, apakah ciri-ciri yang ada pada buruh asing sehinggakan menjadi pilihan kebanyakan kontraktor?. Menurut Mohd Isa et.al. (1999), ciri-ciri buruh asing yang menjadi pilihan majikan adalah seperti berikut:

- Gaji atau upah yang murah.

- Kemahiran yang tinggi.

- Ketekunan.

- Disiplin.

- Sanggup kerja lebih masa.

- Mudah mengikuti arahan kerja.

- Bangsa atau warganegara.

- Komunikasi.

- Kurang masalah sosial.

- Umur dan jantina.

Bagi aspek masalah tenaga buruh binaan tempatan dan asing pula, dapatan literatur mendapati antara masalah-masalah yang dikenal pasti dalam sektor pembinaan adalah seperti berikut:

- Kekurangan buruh tempatan.

- Amalan bayaran gaji atau upah.

- Kualiti kerja.

- Sikap kontraktor.

- Bertukar ke majikan lain.

- Masalah komunikasi.

- Ketidakcekapan.

- Keselamatan.

- Pilihan kerja yang lebih menarik. Behrende (1953) dan Hyman (1970).

- Krisis induksi (Rozhan Othman, 1991).

- Tekanan daripada kekurangan tenaga kerja.

\section{Metod Kajian}

Kaedah menjalankan penyelidikan ini boleh dibahagikan kepada tiga bahagian utama iaitu kajian literatur; pengumpulan data serta analisis dan interpretasi data. Dalam usaha mencapai objektif kajian, kajian yang dijalankan ini meliputi dua fasa iaitu kajian literasi yang mengabungkan pandangan, pendapat dan pendirian pihak kontraktor itu sendiri. Pemahaman akan lebih jelas lagi dengan pembacaan buku-buku teks, media cetak, media masa mahupun elektronik mengenai penggunaan buruh dalam projek pembinaan. Sementara itu, fasa kedua ialah kutipan data-data melalui proses soal selidik dan juga temubual dengan pihak-pihak yang terlibat secara langsung dengan pengambilan pekerja-pekerja asing seperti pihak kontraktor di dalam perlaksanaan kerja pembinaan serta agensi-agensi kerajaan seperti Jabatan Buruh atau Kementerian Sumber Manusia.

Dua kaedah pengumpulan data telah digunakan dalam kajian ini iaitu temebual dan borang soal selidik. Temubual telah dikemukakan kepada pihak kontraktor dan juga pekerja-pekerja di tapak bina. Juga kepada agensi-agensi kerajaan seperti pihak Jabatan Buruh atau sumber manusia. Kaedah temubual akan 
dilakukan secara temubual bebas atau temubual tidak berstruktur. Kaedah temubual dilakukan untuk menyokong data-data yang diperolehi daripada data utama iaitu melalui kaedah soal selidik. Manakala kaedah borang soal selidik merupakan kaedah yang utama dalam kajian ini bagi menjawab objektif kajian. Instrumen yang akan digunakan ini direka bentuk secara soalan tertutup dan juga menggunakan kaedah skala likert dengan lima (5) pilihan jawapan. Borang soal selidik ini terbahagi kepada dua bahagian iaitu A berhubung maklumat kontraktor dan B berkaitan faktor-faktor penyebab buruh asing menjadi pilihan kontraktor iaitu kategori buruh; peratus pekerja mengikut warganegara; peratus pekerja mengikut pecahan buruh; masalah kekurangan tenaga buruh; tahap kesukaran mendapat sumber buruh; kaedah pengambilan buruh asing; kaedah penentuan kemaahiran buruh asing; tahap kualiti kerja buruh asing; ciri-ciri buruh yang menjadi pilihan kontraktor; keutamaan pemilihan buruh oleh kontraktor dan pendapat responden mengenai penggunaan buruh untuk projek akan datang.

Borang soal selidik yang telah direka bentuk telah diedarkan kepada responden yang telah dikenal pasti. Sebanyak 25 set borang telah disediakan kepada responden kajian walaupun dalam kajian ini hanya dibataskan kepada 21 buah syarikat kontraktor sahaja. Tujuannya untuk mengelakkan daripada borang soal selidik yang diserah secara serahan tangan ini tidak dikembalikan dalam kuantiti yang sepatutnya. Kaedah serahan tangan borang soal selidik adalah untuk mengelakkan keciciran seperti borang tidak sampai kepada responden yang dikenal pasti. Namun begitu, pengembalian borang soal selidik yang telah dikemaskini atau dijawab oleh reaponden akan dihantar secara serahan pos. Sehubungan dengan itu juga, kaedah pengembalian secara serahan tangan juga dilakukan sekiranya berlaku kesuntukan masa bagi pihak penyelidik.

Kajian ini dibuat hanya ke atas 21 kontraktor yang sedang menjalankan projek pembinaan yang terletak di kawasan utara semenanjung Malaysia iaitu Negeri Pulau Pinang dan Negeri Kedah Darul Aman. Kajian juga dibataskan kepada kontraktor-kontraktor yang berdaftar dengan Pusat Khidmat Kontraktor (PKK) dan juga Lembaga Pembangunan Industri Pembinaan Malaysia (CIDB) di bawah kelas A hingga F. Ini bermaksud, kesemua kelas kontraktor turut digunakan sebagai responden kajian. Penyelidik berpendapat pemilihan 21 buah syarikat sebagai responden kajian adalah memadai disebabkan oleh kekangan masa dan juga kos dalam pembikinan kajian ini.

Data-data yang telah dikumpul telah dianalisa dengan menggunakan perisian Microsoft Excel dan perisian Statistical Package for the Social Sciences (SPSS). Penggunaan dua perisian ini adalah disebabkan terdapatnya sistem pengaturcaraan statistik yang mudah dan senang untuk digunakan. Datadata di dalam borang soal selidik dianalisis menggunakan kaedah peratusan dan juga purata.

\section{Hasil Kajian}

Analisis mengenai maklumat kontraktor akan merujuk kepada tahun syarikat kontraktor ditubuhkan, kelas pendaftaran kontraktor, pengalaman kontraktor di dalam bidang pembinaan serta bilangan projek yang telah dilaksanakan oleh syarikat kontraktor sehingga sekarang.

Rajah 2 : Penubuhan Syarikat Kontraktor

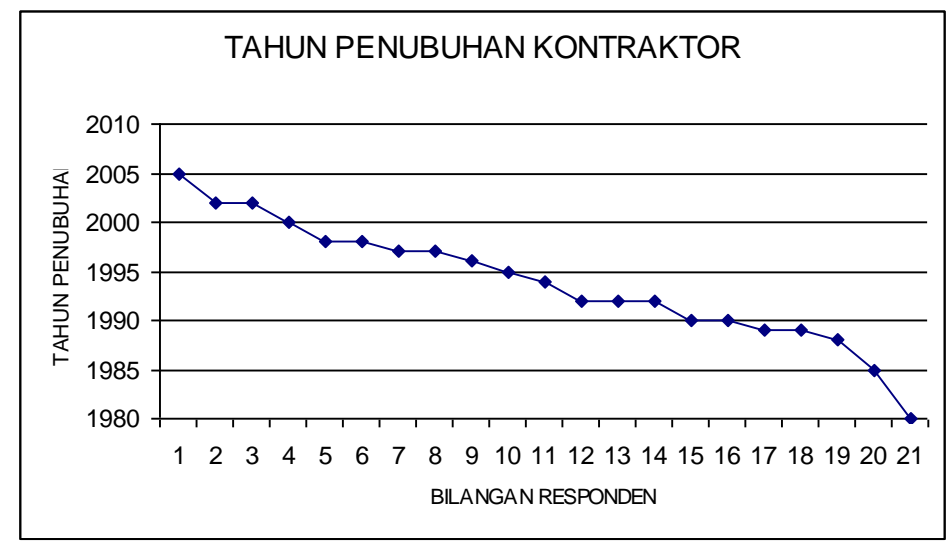


DOI: https://doi.org/10.47405/mjssh.v6i6.811

Berdasarkan analisis data yang telah dibuat mendapati graf taburan bagi penubuhan syarikat responden (dalam tahun) menunjukkan taburan normal iaitu terdapat di antara kontraktor yang telah lama bertapak di dalam bidang pembinaan iaitu sejak tahun 1980 sehinggalah syarikat yang terbaru ditubuhkan iaitu awal tahun 2005 .

Rajah 2 menunjukkan taburan tahun penubuhan syarikat kontraktor. Daripada rajah juga, mendapati bahawa lebih 50 peratus daripada responden mempunyai pengalaman yang melebihi 15 tahun di dalam bidang pembinaan ini. Ini juga menunjukkan bahawa telah ramai buruh digunakan oleh kontraktor di dalam industri ini. Kajian terhadap kelas pendaftaran responden di dalam bidang pembinaan menunjukkan 66.67 peratus mempunyai lesen daripada kelas A, 9.52 peratus daripada kelas B, C dan D. Hanya 4.76 peratus sahaja yang mempunyai lesen kelas $\mathrm{E}$ dan tiada satupun daripada responden yang berkelas $\mathrm{F}$.

Berdasarkan Rajah 3 juga menunjukkan bahawa 66.67 peratus daripada kontraktor merupakan syarikat pembinaan yang bersaiz besar. Ini sudah tentu syarikat-syarikat kontraktor berkenaan mempunyai sumber buruh yang besar dan ramai. Kebanyakan responden yang dikaji merupakan kontraktor bertaraf bumiputera. Hanya 29 peratus sahaja kontraktor bertaraf bukan bumiputera yang dijadikan sampel kajian. Kepelbagaian taraf kontraktor sini juga dapat dilihat bentuk atau corak kaedah pengambilan serta penggunaan tenaga buruh di dalam projek pembinaan mereka. Kadang kala terdapat perbezaan pengurusan sumber buruh di antara kontraktor bumiputera dan juga bukan bumiputera.

Rajah 3 : Kelas Pendaftaran Kontraktor

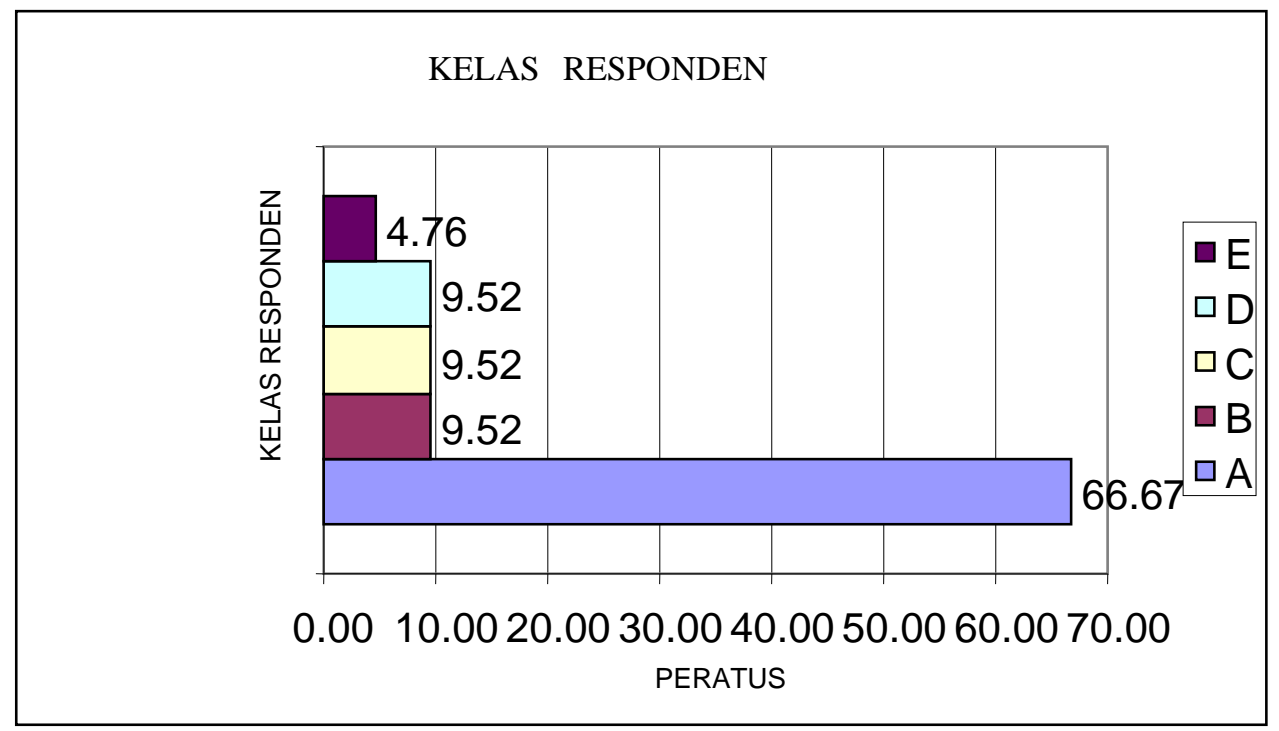

Rajah 4: Taraf Syarikat Kontraktor

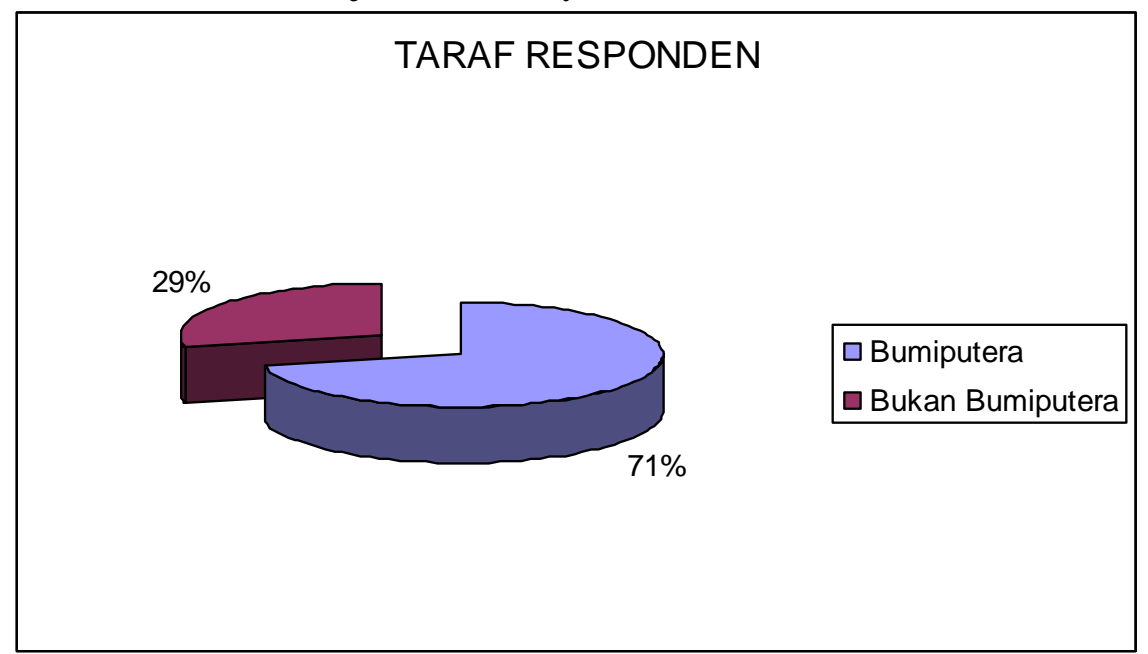


Kebanyakan daripada responden yang dikaji didapati mempunyai pengalaman di dalam sektor pembinaan melebihi 15 tahun iaitu dengan peratusan sebanyak 42.86 peratus. Diikuti pengalaman 11 hingaa 15 tahun dengan 28.57 peratus, 6 hingga 10 tahun 19.05 peratus. Seterusnya 9.52 peratus lagi mempunyai pengalaman antara 1 hingga 5 tahun.

Rajah 5: Pengalaman Kontraktor

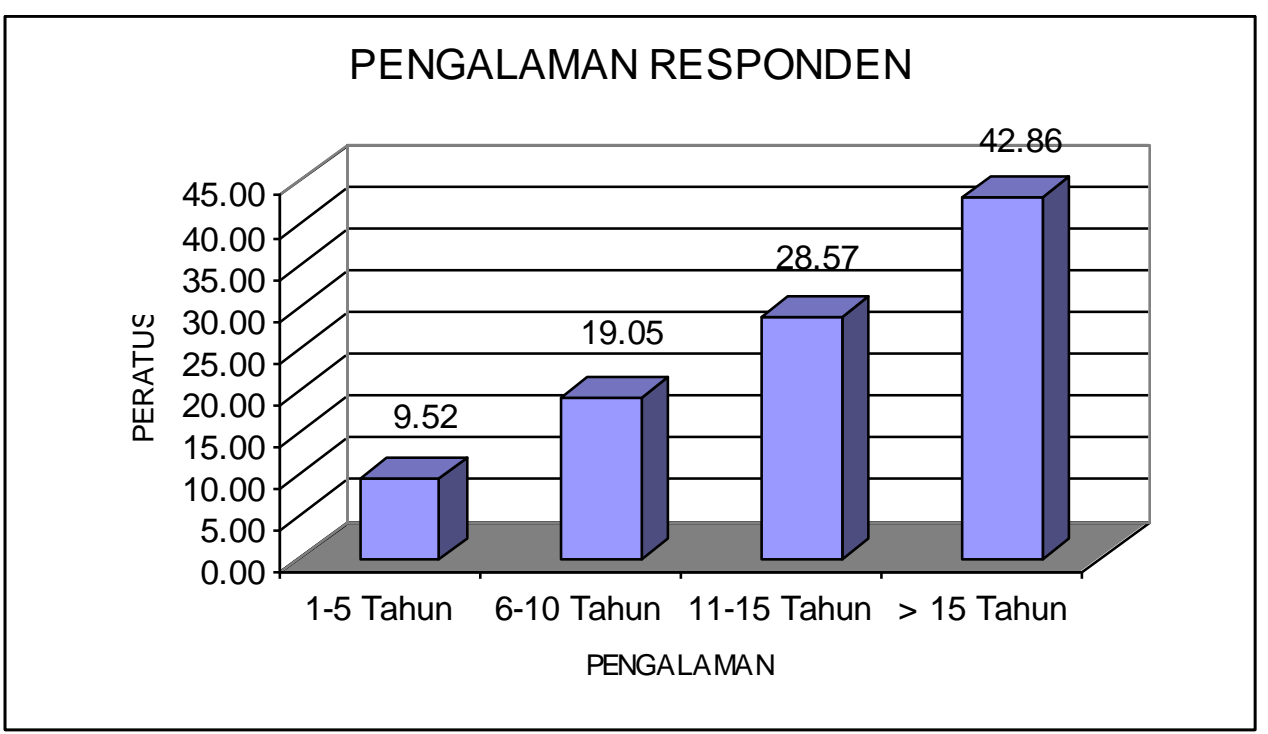

Rajah 6 menunjukkan bilangan projek yang telah dilaksanakan oleh responden hinggalah sekarang menunjukkan 38.10 peratus telah menjalankan projek pembinaan melebihi daripada 30 buah, 33.33 peratus memperolehi projek lingkungan antara 21 hingga 30 buah. Selebihnya, masing-masing dengan peratusan 14.29 peratus adalah antara 11 hingga 20 buah projek dan ada juga yang mendapat kurang daripada 10 buah projek sepanjang syarikat ditubukan.

Rajah 6: Jumlah Bilangan Projek

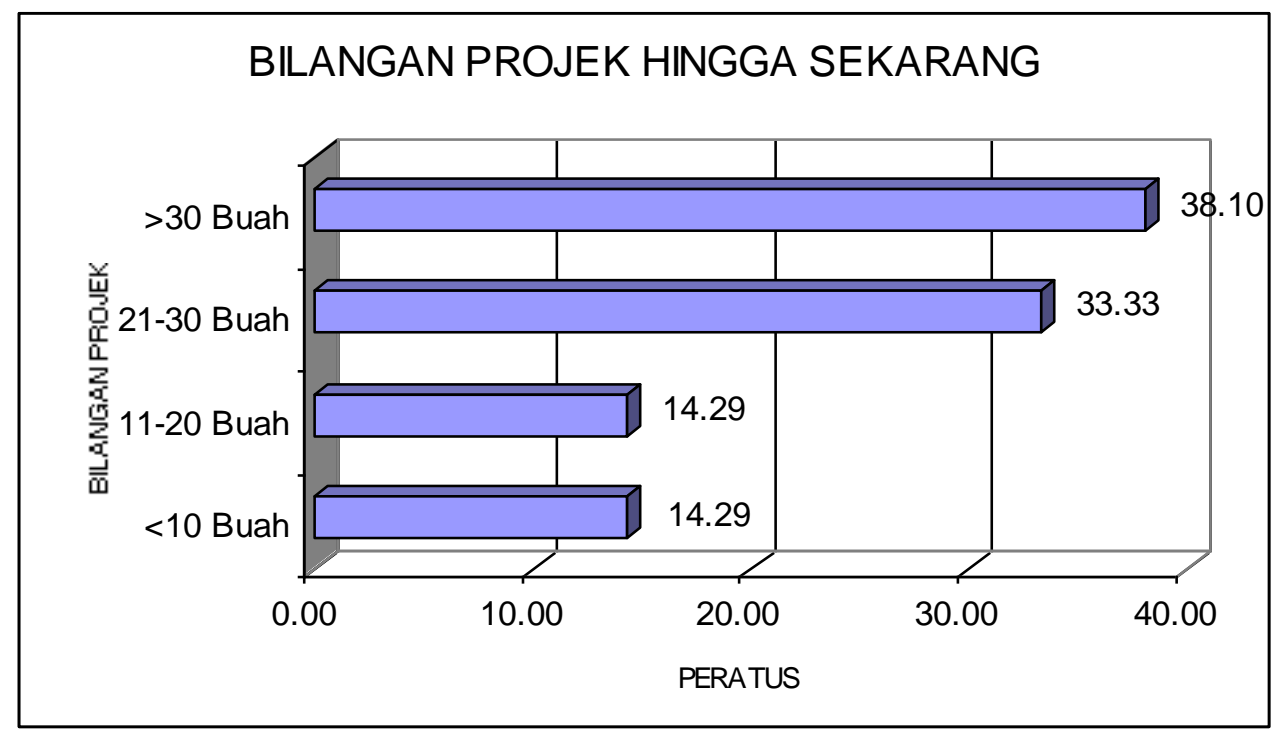

Penggunaan buruh dalam projek pembinaan bertujuan untuk merealisasikan kontrak pembinaan antara pihak klien di dalam bentuk fizikal di mana buruh ini digunakan secara menyeluruh dan pelbagai. Ini bermaksud semua buruh daripada pelbagai jenis buruh seperti tukang kayu, bata, besi, konkrit, tukang pasang kemasan, tukang cermin dan sebagainya digabungkan untuk menyiapkan projek pembinaan. 
Apabila dihuraikan mengenai penggunaan buruh maka ianya berkait dengan kos dan juga kualiti kerja. Kos buruh mewakili 20 peratus daripada keseluruhan kos dan semakin mengecil kos buruh dapat dilakukan, maka semakin besar keuntungan yang diperolehi oleh syarikat kontraktor. Oleh itu, sebagai alternatifnya buruh asing digunakan untuk mengurangkan kos pengurusan kontraktor di samping mendapatkan mutu kerja yang tinggi. Namun begitu, bagaimana pula dengan buruh tempatan? Mengapa ianya semakin dipinggirkan oleh pihak kontraktor untuk digunakan di dalam projek-projek mereka. Dapatan kajian mengenai analisis faktor ini, sebanyak 11 perkara telah dicungkilkan untuk menjawab objektif kajian seperti pecahan tenaga buruh mengikut kategori, peratus pekerja mengikut warganegara, tenaga buruh mengikut pecahan, masalah kekurangan tenaga buruh, kaedah pengambilan pekerja, penentuan kemahiran, tahap kualiti buruh asing, ciri-ciri buruh pilihan kontraktor, keutamaan ciri pilihan buruh oleh kontraktor serta maklum balas kontraktor mengenai penggunaan buruh di mana akan datang. Kebanyakan kontraktor yang dikaji menggunakan khidmat buruh secara sub kontrak berbanding buruh langsung. Penggunaan sub buruh secara penuh memudahkan pengurusan, penyeliaan dan pengawalan dilakukan di tapak. Kaedah pengambilannya mudah di mana perlu mendapatkan kepala buruh atau ketua buruh. Segala kerja atau maklumat hanya akan diarahkan kepada kepala buruh sahaja. Mengenai kos upah pula ianya dibayar secara pukal tanpa mengambil kira bilangan buruh yang digunakan. Berbeza dengan sistem buruh langsung di mana sistem pembayaran akan dilakukan terus kepada pekerja. Begitu juga dengan pengagihan kerja di mana perlu diberitahu atau diberi taklimat mengenai kerja yang harus dilakukan oleh pekerja berkenaan. Sistem sub buruh biasanya digunakan untuk melakukan kerja-kerja yang terhad seperti kerja mengecat, kerja kayu dan konkrit, kerja jubin dan sebagainya.

Secara keseluruhannya, semua kontraktor yang dikaji menggunakan kedua-dua jenis buruh iaitu buruh tempatan dan juga buruh asing. Namun begitu, secara statistiknya buruh asing digunakan dalam jumlah yang ramai berbanding dengan buruh tempatan. Hanya suku daripada jumlah buruh adalah dari kalangan buruh tempatan dan yang selebihnya daripada buruh asing. Buruh asing dari Negara Indonesia mewakili peratusan yang paling tinggi di kalangan lain-lain buruh. Jumlahnya hampir menyamai bilangan buruh tempatan. Mengikut laporan terbaru yang dikeluarkan oleh Unit Perangkaan Negara, di Malaysia terdapat hampir 1.8 juta buruh asing pada tahun 2007 dan 500 ribu daripadanya adalah buruh asing tanpa izin (PATI).

Berdasarkan kepada pecahan buruh pula iaitu buruh mahir, sederhana mahir dan juga buruh am, perbandingan antara buruh asing dengan buruh tempatan adalah 2 nisbah 1 bagi kategori buruh sederhana mahir dan juga buruh am. Namun begitu bagi buruh mahir, jumlahnya adalah melebihi sedikit bagi buruh tempatan berbanding dengan buruh asing (beza 7 peratus sahaja) di kebanyakan tapak bina. Ini menunjukkan penggunaan buruh mahir dari kalangan warga asing amat ramai digunakan oleh pihak kontraktor. Kesukaran di dalam mendapatkan khidmat buruh tempatan oleh pihak kontraktor menyebabkan buruh asing digunakan. Dapatan kajian mendapati, peratusan kesukaran di dalam mendapatkan khidmat buruh tempatan adalah hampir sebahagian daripada kontraktor. Bagi pihak kontraktor juga, selain daripada masalah mendapatkan buruh tempatan, masalah kekurangan tenaga buruh juga sering berlaku apabila kontraktor mendapat banyak projek dalam masa yang sama (serentak). Lebih separuh daripada kontraktor akan mengalami masalah ini. Oleh itu, punca-punca kekurangan buruh seperti inilah yang menyebabkan khidmat buruh asing diperlukan. Begitu juga keadaanya sekiranya pihak kontraktor mendapat kontrak kerja yang perlu disipakan secara segera atau dalam tempoh yang singkat. Biasanya keadaan ini berlaku apabila tawaran projek dilakukan secara rundingan terus oleh pihak majikan. Tempoh yang diberikan untuk kontraktor menyiapkan kerja adalah kurang daripada setahun dan ini memerlukan kepada kontraktor yang mempunyai keupayaan yang tinggi baik dari segi kewangan, teknikal dan pengurusan yang cekap untuk menjayakannya.

Dalam pengambilan tenaga buruh oleh pihak kontraktor, kaedah pengambilan buruh asing adalah melalui ejen pekerja asing di Malaysia. Berbanding dengan lain-lain kaedah seperti pejabat buruh, rakan kenalan, temuduga serta ejen pekerja asing di Negara asal pekerja, kaedah ini lebih menjimatkan kos, masa dan juga waktu pencarian buruh tidak lama. Melalui kaedah ini, kontraktor kebanyakannya akan mendapat khidmat buruh yang mahir, kos upah yang rendah serta boleh bekerja tanpa mengira lokasi tapak projek. Ini bermaksud, buruh yang diambil bekerja akan menetap di tapak bina sehinggalah projek berkenaan siap sepenuhnya. Begitu juga dengan kaedah penentuan kemahiran buruh asing di mana pihak kontraktor akan menyerahkan urusan ini kepada pihak ejen pekerja asing untuk menentukan pekerja yang betul-betul 
mahir mengikut tred yang ditentukan. Lain-lain kaedah yang digunakan adalah kaedah jaminan oleh sub kontraktor, jaminan rakan kenalan, dipilih oleh kepala buruh dan juga mengadakan ujian kemahiran oleh kontraktor.

\section{Perbincangan Kajian}

Dapatan kajian terhadap tahap kualiti buruh asing pula, secara puratanya kebanyakan pihak kontraktor berpuashati dengan kualiti kerja yang ditunjukkan oleh pekerja asing. Ini termasuk bagi kategori buruh mahir dan sederhana mahir. Namun, bagi buruh buruh am kualiti yang ditunjukkan adalah hampir seragam iaitu, amat berpuashati, puashati, sederhana, tidak berpuashati dan ada juga yang sangat-sangat tidak menunjukkan kualiti kerja yang diharapkan. Ini disebabkan oleh penggunaan buruh yang hampir sama sekali tidak mempunyai sebarang kemahiran dan datang ke Malaysia semata-mata hendak mendapatkan pekerjaan sahaja. Mengenai ciri-ciri buruh pilihan kontraktor pula, jika dibandingkan antara buruh tempatan dengan buruh asing, dapatan kajian mendapati buruh asing lebih menjadi pilihan pihak kontraktor berbanding dengan buruh tempatan. Ciri-ciri yang menjadi pilihan kontraktor adalah buruh asing kebanyakannya sanggup menerima upah yang rendah namun kualiti kerja yang ditunjukkan adalah tinggi. Lebih sebahagian daripada kontraktor yang menggunakan khidmat pekerja asing dibayar dengan upah yang murah. Berbanding dengan buruh tempatan, pihak kontraktor jarang menggunakan khidmat mereka disebabkan permintaan terhadap kadar upah yang tinggi serta jauh berbeza dengan dari yang ditawarkan oleh buruh asing.

Dari segi kemahiran kerja pula, dapatan kajian mendapati buruh asing lebih mahir berbanding dengan buruh tempatan di dalam banyak kerja. Kerja-kerja seperti kerja-kerja kayu dan ketukangan, melepa, mengikat bata, mengecat dan memasang jubin banyak dilakukan oleh buruh asing. Buruh yang mahir mampu melakukan kerja dalam masa yang singkat, kurang pembaziran serta mampu melakukan kerja di dalam keadaan yang sukar dan ciri-ciri seperti ini ada pada buruh asing. Namun begitu, keadaan ini mungkin berbeza di lain-lain tempat dan lokasi di mana buruh tempatan lebih baik mutu kerjanya berbanding buruh tempatan. Ketahanan kerja atau tahan lasak merupakan satu ciri fizikal yang ada pada seseorang. Pekerja yang tahan lasak boleh melakukan kerja dalam pelbagai keadaan terutama di dalam cuaca yang panas atau lembap. Dapatan kajian mendapati lebih separuh daripada kontraktor memilih buruh asing disebabkan ciri ketahanan kerja yang ada pada mereka. Buruh asing sanggup dan mampu melakukan kerja di tempat-tempat yang tinggi atau kawasan yang berisiko dengan selamat. Aspek imbuhan atau upah yang diberikan mendorong buruh asing sanggup melakukan kerja-kerja ini berbanding dengan buruh tempatan di mana akan meminta upah yang berbeza sekiranya melibatkan kerja yang berisiko tinggi. Buruh asing juga boleh melakukan kerja tidak mengikut masa. Mereka akan tetap bekerja walaupun pada hari cuti umum atau selepas waktu kerja. Sifat kerajinan yang ditunjukkan ini mampu memberi kesan positif kepada penyiapan keseluruhan projek.

Aspek komunikasi serta mudah memahami arahan kerja ada pada buruh tempatan. Buruh tempatan dapat berkomunikasi dengan baik serta mudah untuk diarahkan di dalam menjalankan kerja. Berbeza dengan buruh asing di mana aspek komunikasi, arahan kerja serta memerlukan penyeliaan di dalam menjalankan kerja. Faktor bahasa menjadi sedikit penghalang kepada mereka untuk bekerja secara berkesan. Namun berbeza kepada buruh warga Indonesia di mana faktor ini jarang manjadi masalah kepada mereka. Ianya disebabkan oleh bahasa yang digunakan mereka hampir sama dengan bahasa Malaysia iaitu bahasa melayu Indonesia.

Melihat dari sudut disiplin kerja pula, buruh asing lebih baik berbanding dengan buruh tempatan. Lebih separuh daripada kontraktor mengakui bahawa buruh asing lebih berdisiplin dalam melakukan kerja. Ini mungkin disebabkan oleh faktor bekerja di negara orang menyebab mereka ini lebih menghormati negara asing. Namun begitu, jika dilihat kepada kerenah dalam kerja, hampir kesemua kontraktor menyatakan bahawa aspek ini tiada sama sekali pada diri pekerja sama ada buruh asing mahupun buruh tempatan. Kerja sepasukaran merupakan satu aktiviti secara kerjasama dalam kumpulan. Dapatan kajian menunjukkan bahawa buruh asing boleh bekerja secara berpasukan antara mereka dan juga dengan buruh tempatan. Peratusan yang tinggi diperolehi daripada analisis kajian dan ini telah memberi kesan yang baik 
kepada projek pembinaan. Setiap pekerja perlu melakukan secara kerjasama untuk mendapatkan hasil yang lebih baik dan dapat menjimatkan masa operasi.

Kajian ke atas ciri-ciri pemilihan buruh yang menjadi keutamaan kepada kontraktor menunjukkan bahawa buruh asing masih lagi menjadi pilihan kontraktor berbanding buruh tempatan. Aspek-aspek seperti pekerja lelaki, umur 18 hingga 40 tahun, upah yang rendah, kemahiran yang tinggi, ketahanan kerja, sanggup bekerja lebih masa merupakan kriteria yang ada pada buruh asing dan diperlukan oleh kontraktor. Namun begitu, ciri-ciri seperti bangsa, agama, jantina wanita, umur melebihi 40 tahun, mahir berbahasa, kebolehan menulis dan sebagai merupakan ciri-ciri yang tidak menjadi keutamaan kepada kontraktor dalam pemilihan seseorang buruh.

\section{Kesimpulan}

Secara keseluruhannya, buruh asing memang menjadi pilihan kebanyakan kontraktor berbanding buruh tempatan. Perspeksi ini menunjukkan bahawa penggunaan tenaga buruh asing semakin mendapat tempat di kebanyakan projek-projek pembinaan. Dengan pembangunan negara yang semakin berkembang penggunaan buruh asing perlu dikurangkan. Begitu juga dengan pekerja tempatan di mana peluang untuk membangun negara perlulah diambil sebaik-baiknya agar masalah pengangguran dapat dikurangkan.

Hasil daripada dapatan kajian ini maka, dicadangkan agar cadangan-cadangan ini mampu memberi sumbangan kepada sektor pembinaan khasnya serta pihak-pihak yang terlibat di dalamnya. Antara cadangan adalah seperti berikut:

- Pihak kontraktor haruslah lebih realistik di dalam mengambil tenaga kerja di mana harapan agar aspek upah yang rendah tidak menjadi keutamaan dalam pemilihan buruh.

- Pihak kerajaan seperti Jabatan Kerja Raya atau Pusat Khidmat Kontraktor dan juga Lembaga Pembangunan Industri Binaan Malaysia dapat mengeluarkan jadual kadar upah yang seragam dan perlu ada penguatkuasaan terhadap upah yang diberikan oleh pihak kontraktor kepada pekerja.

- Pihak kerajaan perlu mengurangkan pengambilan buruh asing agar masalah kebanjiran buruh asing dapat dikurangkan.

- Pihak kerajaan perlu memperbanyakkan penubuhan institusi berasaskan kemahiran untuk menampung perkembangan di sektor pembinaan.

- Pekerja tempatan perlu memperlengkapkan diri dengan ciri-ciri kemahiran kerja dan juga soft skill.

\section{Rujukan}

Ahmad Sobri Bin Lebai Isa (2005). Penggunaan Buruh Di Kalangan Kontraktor Kontraktor Di Negeri Kedah. Universiti Teknologi Malaysia : Tesis Sarjana Muda.

Behrende, H. (1953). Absence and Labour Turnover in Changing Economic Climate. Accupational Psychology.

Don Bellante dan Mark Jackson (1989). Ekonomi Buruh. Terjemahan Nazlifa Md Ali. Kuala Lumpur : Dewan Bahasa dan Pustaka.

Hapriza Ashari (2004). Undang-Undang Pekerjaan - Huraian dan Panduan Terhadap Akta Kerja 1955. Johor Darul Takzim : Universiti Teknologi Malaysia.

Hyman, R(1970). Economic Motivation and Labour Stability, The British Journal of Industrial Relation. Laporan Bajet 2007.Berita Harian.Online (2006).

Laporan Berita Harian, 30 Januari (2002).

Laporan Ekonomi. Utusan Malaysia, September (2004).

Laporan Utusan Malaysia, 25 Januari (2002). 
Mhd Azmin Bin Mat Seman (2001). Implikasi Pengurusan Penghantaran Bahan Terhadap Kos Bagi Pembinaan Di Pulau Terpencil. Universiti Teknologi Malaysia : Tesis Sarjana Muda.

Mohd Asri Abdullah (1997). Economic Growth and Foreign Labour in Malaysia: Some Socio-economic Implication on the Local. A paper presented at the National Conference on Economic Growth and Quality of life in Malaysia. The School of Economics, Universiti Utara Malaysia, Sintok, Kedah.

Mohd Isa, AHM Zehadul Karim dan Moha Asri Abdullah (1999). Foreign Workers in Malaysia - Issues and Implication. Kuala Lumpur: Utusan Publication \& Distributors Sdn. Bhd.

Pekerja Asing: Kementerian Bincang Dengan Majikan, Berita Harian, 30 Januari (2002).

Rahzan Othman (1991). Pengurusan Personel dan Perancangan Guna Tenaga. Kuala Lumpur: Dewan Bahasa dan Pustaka.

Teoh Chew Chee (1986). Retrenchment: How big a threat, Investor Digest, Mild.

The long and Short Of Foreign Labour, The Star, 14 Mac (2005).

Warga Bangla Tidak Boleh Bekerja Di Semua Sektor, Berita Harian, 7 Februari (2002). 